\title{
Sistemas ligantes para concretos refratários mulitizáveis
}

\section{(Binding systems for mulitized castables)}

\author{
M. V.M.Magliano, V. C.Pandolfelli \\ Grupo de Engenharia de Microestrutura de Materiais - GEMM, Universidade Federal de S. Carlos, \\ Departamento de Engenharia de Materiais, Rod. Washington Luiz, km 235, C.P. 676, S. Carlos, SP 13565-905 \\ vinicius@plugnet.com.br,vicpando@power.ufscar.br
}

\begin{abstract}
Resumo
Concretos mulitizados são comumente utilizados na indústria siderúrgica devido as suas excelentes propriedades. Entretanto, a presença de cimento de aluminato de cálcio, juntamente com $\mathrm{SiO}_{2}$, forma eutéticos e fases de baixo ponto de fusão, motivando assim a seleção de ligantes alternativos. Neste trabalho os três principais ligantes para refratários (cimento de aluminato de cálcio, alumina hidratável e sílica coloidal) foram incorporados em concretos com alto potencial de mulitização e suas propriedades a verde e a quente foram comparadas, definindo quais ligantes apresentam melhor desempenho. Os resultados indicam que a sílica coloidal, além de facilitar a etapa de secagem, resulta em excelentes propriedades a quente e em menor teor de líquido residual após queima, quando comparados com uma composição referência de alta alumina.

Palavras-chave: sílica coloidal, sistema ligante, mulita, concreto refratário.
\end{abstract}

\begin{abstract}
Mullite based castables are usually applied for lining steel industries processing ladles due to their superior working performance. However, the presence of aluminate cement and $\mathrm{SiO}_{2}$ can deteriorate their hot properties by the formation of eutectics and low melting point phases, which motivates the search for alternatives biding systems. In this paper, the three main binders for refractory castables (aluminate cement, hydratable alumina and colloidal silica) were added to different compositions and their green and hot properties were compared, aiming to define which one presents better performance. The results indicated the colloidal silica as a promising substitute to the aluminate cement as it favors the drying process, provides excellent hot properties, higher refractoriness and generates low residual liquid phase after sintering, when compared to a high alumina composition.
\end{abstract}

Keywords: colloidal silica, binding system, mullite, refractory concrete.

\section{INTRODUÇÃO}

Concretos refratários são materiais comumente utilizados para aplicações a altas temperaturas, como revestimentos de fornos, fabricação de peças e componentes internos de equipamentos, entre outros. Historicamente, tijolos e peças pré-formadas eram os principais materiais utilizados na produção de aço e em outros processos industriais que exigem exposição à alta temperatura, pois a geometria dos fornos era simples e o formato dos tijolos atendia as necessidades das indústrias. Além disso, os concretos refratários possuíam refratariedade consideravelmente inferior que os tijolos, devido aos mesmos utilizarem alto teor de cimento.

Com o aprimoramento da logística de fabricação do aço, processos mais produtivos foram desenvolvidos, resultando em equipamentos com geometrias mais complexas e necessidade de menores tempos de parada dos fornos, pressionando o desempenho dos refratários. Tendo em vista a limitação dos tijolos em relação a formas e o elevado tempo de reparo e instalação dos mesmos, a utilização de concretos tornou-se viável tanto do ponto de vista técnico como do econômico. A necessidade industrial motivou pesquisas e desenvolvimentos no campo de concretos refratários e cimentos com maior poder ligante e refratariedade $[1,2]$. Um grande marco na indústria de refratários foi o desenvolvimento de concretos com baixo teor de cimento, que permitiu a substituição dos tijolos pelos concretos, gerando inúmeras vantagens aos usuários de refratários.

A possibilidade de moldar formas complexas, como cilindros e abóbadas, menor tempo necessário para instalação e maior facilidade de automação, menor custo de produção (pois este não requer pré-queima), ausência de juntas, que são locais favoráveis a corrosão, e maior facilidade de realizar reparos e manutenção, são algumas das vantagens desses materiais. Essa tecnologia permitiu que a indústria do aço utilizasse cada vez mais esses materiais em seus processos produtivos demandando, com isso, maior desenvolvimento dos concretos.

A evolução dos concretos está intimamente relacionada ao desenvolvimento de melhores ligantes, que facilitem a 
aplicação e que possuam elevado desempenho durante o uso [3]. Os ligantes comumente utilizados na fabricação de concretos possuem pega hidráulica e reagem com água a fim de formar uma estrutura que forneça resistência mecânica a verde suficiente ao sistema. Entre esses se destacam o tradicional cimento de aluminato de cálcio e as aluminas hidratáveis. Entretanto, estes ligantes apresentam alguns problemas em sua utilização. O cimento de aluminato de cálcio (CAC) possui alto teor de $\mathrm{CaO}$, que juntamente com a sílica, elemento presente em concretos mulitizáveis, formam fases de baixo ponto de fusão, prejudicando o desempenho do material em altas temperaturas. Além disso, esses refratários possuem baixa permeabilidade após cura, o que gera a necessidade de um tempo de secagem longo para que ocorra a saída da água sem risco de explosão. Ao perder esta água de hidratação, esses materiais têm sua porosidade aumentada reduzindo a resistência ao desgaste e corrosão.

Aluminas hidratáveis (AH), também usadas como ligante, não apresentam a restrição da formação de fases de baixo ponto de fusão em sistemas mulitizados. Entretanto, a permeabilidade desses materiais após cura é ainda mais baixa que os refratários com cimentos. Neste caso, a hidratação da alumina durante a cura forma um gel que preenche os espaços vazios, vedando os canais para saída de água. Portanto, a etapa de secagem se torna crítica, aumentando o tempo e o risco de explosão. Adicionalmente, o tempo de mistura dessas geralmente é superior aos outros ligantes $[4,5]$.

Hoje, com a forte presença da nanotecnologia em quase todos os campos de pesquisa, ligantes nanoestruturados têm sido desenvolvidos entre os quais se destaca a sílica coloidal. Esta se apresenta como um ligante não hidráulico, capaz de gerar resistência mecânica a verde suficiente para a aplicação. A sílica coloidal tem o potencial de resultar superior refratariedade devido à ausência de $\mathrm{CaO}$ e de álcalis em sua composição. Durante a pega ocorre a formação de um gel contendo nano poros que aumentam a permeabilidade, diminuindo drasticamente o tempo de secagem. A pega desses materiais não ocorre por hidratação (ligante não hidráulico), portanto, durante a secagem, não é gerada tensão interna devido a pressurização da saída da água estrutural, como no caso dos ligantes hidráulicos. Tal diferencial reduz consideravelmente o risco de explosão [6, 7]. A cura desses concretos pode ser feita em tempos mais curtos que os cimentos ou aluminas hidratáveis, pois a pega ocorre juntamente com a retirada da água do sistema, não havendo necessidade de tempo para que ocorram reações de hidratação. Outra vantagem é a não liberação de calor durante o processo. Baseado nestes aspectos, trabalhos comprovando a eficácia da sílica coloidal como ligante a verde têm sido realizados $[3,6,7]$ e suas propriedades são comumente comparadas com as dos concretos ligados por CAC como referência. Entretanto, estudos comparativos das propriedades a quente desses materiais são escassos e algumas vezes tendenciosos, uma vez que são principalmente efetuadas pelos produtores.
O objetivo principal desse trabalho é comparar propriedades a quente de concretos mulitizáveis utilizando diferentes ligante: sílica coloidal, CAC e alumina hidratável, adequando cada sistema ao melhor procedimento de processamento e estabelecendo informações tecnológicas quanto ao efeito de cada ligante, tanto nas propriedades a quente como na quantidade de fase líquida e de mulita gerada.

\section{MATERIAIS E MÉTODOS}

Foram formuladas quatro composições mulitizáveis, utilizando-se os seguintes ligantes: sílica coloidal, cimento de aluminato de cálcio, alumina hidratável $(\mathrm{AH})$ e sílica coloidal juntamente com AH. Esses sistemas possuem em sua matriz $24 \%$ de $\mathrm{SiO}_{2}$ e $76 \%$ de $\mathrm{Al}_{2} \mathrm{O}_{3}$. Foi ainda formulada uma composição referência de alta alumina, sem a presença de sílica, para se ter um padrão de comparação das propriedades.

\section{Formulação dos concretos e processamento}

As composições foram formuladas utilizando-se o software PS Designer, desenvolvido no GEMM. Todas as composições continham em sua matriz $24 \%$ de $\mathrm{SiO}_{2}$ e $76 \%$ de $\mathrm{Al}_{2} \mathrm{O}_{3}$, e a quantidade de agregados era próxima de $70 \%$ p. O coeficiente de empacotamento utilizado foi Andreasen $q=0.21$. A Tabela I apresenta as matérias primas utilizadas nesse trabalho.

Tabela I - Matérias primas utilizadas neste trabalho. [Table I - Raw materials used in this work.]

\begin{tabular}{cc}
\hline Material & Especificações \\
\hline Alumina eletrofundida marrom & 4/10, 8/20, 20/40, TP40 \\
& TP 200 \\
Alumina calcinada & A1000SG, CL370 C \\
Microssílica & MS971U \\
Cimento de aluminato de cálcio & Secar 71 \\
Alumina hidratável & Alfabond 300 \\
Sílica coloidal & Nalco (40\% p) \\
\hline
\end{tabular}

Os concretos foram processados em um reômetro [8], segundo o procedimento descrito a seguir. A Tabela II mostra os sistemas estudados e as quantidades de aditivos dispersantes e teor de água utilizada. Nos concretos contendo sílica coloidal primeiramente foi adicionada uma pequena quantidade de água (Tabela II) em baixa rotação (20 rpm), posteriormente esta foi aumentada para $55 \mathrm{rpm}$ e o ligante coloidal adicionado. $\mathrm{O}$ tempo de mistura foi próximo a 300 s para os sistemas CAC, $\mathrm{CAC}+\mathrm{MS}$ e $\mathrm{SC}+\mathrm{MS}$. Os sistemas contendo alumina hidratável necessitaram de um tempo de mistura superior, aproximadamente $500 \mathrm{~s}$. Os aditivos dispersantes foram adicionados e previamente misturados no pó ainda seco. As composições contendo CAC foram 
Tabela II - Formulações das matrizes: $\mathrm{CAC}=$ cimento de aluminato de cálcio. $\mathrm{MS}=$ microssílica . $\mathrm{SC}=$ sílica coloidal. $\mathrm{AB}=$ Alfabond.

[Table II - Matrix compositions: $C A C=$ calcium aluminate cement. $M S=$ microsilica. $S C=$ colloidal silica. $A B=$ Alfabond.]

\begin{tabular}{|c|c|c|c|c|c|c|}
\hline Composição & $\mathrm{SC}(\%)$ & $\operatorname{MS}(\%)$ & $\begin{array}{c}\mathrm{AB} \text { ou } \\
\mathrm{CAC}(\%)\end{array}$ & $\begin{array}{l}\text { Água } \\
(\%)\end{array}$ & $\begin{array}{c}\text { Total de água } \\
\text { (\%) }\end{array}$ & $\begin{array}{c}\text { Quantidade } \\
\text { Aditivo }\end{array}$ \\
\hline CAC & - & 0,0 & 2,0 & 4,50 & 4,50 & $\begin{array}{c}\text { Ac. cítrico } \\
0,03 \%\end{array}$ \\
\hline $\mathrm{CAC}+\mathrm{MS}$ & - & 7,2 & 1,5 & 5,0 & 5,0 & FS $20 \quad 0,13 \%$ \\
\hline $\mathrm{MS}+\mathrm{AB}$ & 0 & 7,2 & 3,0 & 5,25 & 5,25 & $\begin{array}{c}\text { Ac. cítrico } \\
0,20 \%\end{array}$ \\
\hline $\mathrm{SC}+\mathrm{MS}+\mathrm{AB}$ & 5 & 5,2 & 3,0 & 1,50 & 4,50 & $\begin{array}{c}\text { Ac. cítrico } \\
1,80 \%\end{array}$ \\
\hline $\mathrm{SC}+\mathrm{MS}$ & 5 & 5,2 & 0,0 & 1,50 & 4,50 & $\begin{array}{c}\text { Ac. cítrico } \\
0,06 \%\end{array}$ \\
\hline
\end{tabular}

curadas a $50{ }^{\circ} \mathrm{C}$ por $12 \mathrm{~h}$, em ambiente saturado por vapor de água. As composições contendo sílica coloidal (SC), e Alfabond $(\mathrm{AB})$ foram curadas a $110{ }^{\circ} \mathrm{C}$ em ambiente insaturado por $12 \mathrm{~h}$.

\section{Resistência mecânica e porosidade}

Para a medida da resistência mecânica foi utilizada uma maquina de ensaio universal MTS 810. O ensaio a verde foi realizado por compressão diametral (ASTM C 496-90) em corpos de prova cilíndricos de $\mathrm{h}=\mathrm{d}=40 \mathrm{~mm}$, logo após a cura. Quatro amostras foram utilizadas por composição.

A resistência após queima foi realizada por flexão 3 pontos em barras de $150 \mathrm{~mm}$ x $25 \mathrm{~mm} 25 \mathrm{~mm}$, (norma ASTM C13397, 2003). Para cada sistema foram utilizadas 5 barras préqueimadas a $1500{ }^{\circ} \mathrm{C}$ por $10 \mathrm{~h}$.

A porosidade aparente foi medida pelo método de imersão de Arquimedes, utilizando água como líquido de acordo com a norma ASTM C830-88.

\section{Ensaio de explosão}

Foi utilizada uma balança eletrônica acoplada a um forno elétrico. No ensaio, uma amostra cilíndrica de $\mathrm{h}=\mathrm{d}=40$ $\mathrm{mm}$ é aquecida perdendo massa devido à saída de água. $\mathrm{O}$ equipamento registra a temperatura e a massa do corpo ao longo do tempo. Um gráfico onde a taxa de perda de massa é acompanhada com a variação da temperatura foi utilizado para as análises. $\mathrm{O}$ teste foi realizado imediatamente após a cura, utilizando-se uma taxa de aquecimento de $20^{\circ} \mathrm{C} / \mathrm{min}$ até a temperatura de $800{ }^{\circ} \mathrm{C}$.

\section{Refratariedade sob carga}

O ensaio foi realizado no equipamento Netzsch RUL 421E em corpos de prova cilíndricos, de dimensões $\mathrm{h}=\mathrm{d}=50 \mathrm{~mm}$ contendo um furo central de $12,5 \mathrm{~mm}$ pré-queimados a $1500^{\circ} \mathrm{C}$ por $10 \mathrm{~h}$. A taxa de aquecimento foi de $5^{\circ} \mathrm{C} / \mathrm{min}$ até $1600{ }^{\circ} \mathrm{C}$, sendo aplicada uma carga compressiva de 0,2 MPa.

\section{Módulo de ruptura a quente}

O ensaio de resistência mecânica a quente foi realizado a $815,1200,1300,1400 \mathrm{e} 1450^{\circ} \mathrm{C}$, em amostras pré-queimadas por $10 \mathrm{~h}$ nas devidas temperaturas. Barras de $(150 \mathrm{~mm} \mathrm{x}$ $25 \mathrm{~mm} \times 25 \mathrm{~mm}$ ) foram ensaiadas em um equipamento de flexão 3 pontos Netzsch HBST (High Bending Strength Tester) 422, de acordo com a norma ASTM C 583-8.

\section{Choque térmico}

No ensaio, barras $(150 \mathrm{~mm} \times 25 \mathrm{~mm} \times 25 \mathrm{~mm})$ préqueimadas a $1500{ }^{\circ} \mathrm{C}$ por $10 \mathrm{~h}$ são colocadas dentro de um forno tubular pré-aquecido a $1015{ }^{\circ} \mathrm{C}$ por $15 \mathrm{~min}$, sendo posteriormente retiradas e expostas ao ar por mais $15 \mathrm{~min}$ $\left(\Delta \mathrm{T} \approx 1000{ }^{\circ} \mathrm{C}\right)$, completando assim 1 ciclo térmico. Foram realizados no total 7 ciclos térmicos por corpo de prova. $\mathrm{O}$ dano sofrido com o choque térmico foi identificado pela queda do módulo elástico (E) em função do número de ciclos aplicados. Foram realizadas medidas de $\mathrm{E}$ antes do inicio do ensaio, após o primeiro ciclo, o segundo, o quinto e o sétimo ciclo. Para a medida do módulo elástico utilizou-se o método de ressonância de barras. As freqüências de ressonância e o cálculo do módulo foram efetuadas no equipamento Escaneslatic, desenvolvido em parceria GEMM/DEMa/ UFSCar - ATCP do Brasil.

\section{RESULTADOS E DISCUSSÃO}

\section{Resultados a verde}

A análise da Fig. 1 mostra que os valores de resistência mecânica a verde para os sistemas AB+MS e CAC+MS não apresentaram diferenças significativas, indicando que o poder de ligação dos mesmos é equivalente. Já os valores obtidos com SC foram superiores.

Oensaio de explosão (Fig.2) evidencia as diferenças entre os ligantes. Dentre os sistemas testados, os que utilizaram ligantes hidráulicos $(\mathrm{CAC}+\mathrm{MS}$ e $\mathrm{AB}+\mathrm{MS})$ explodiram 


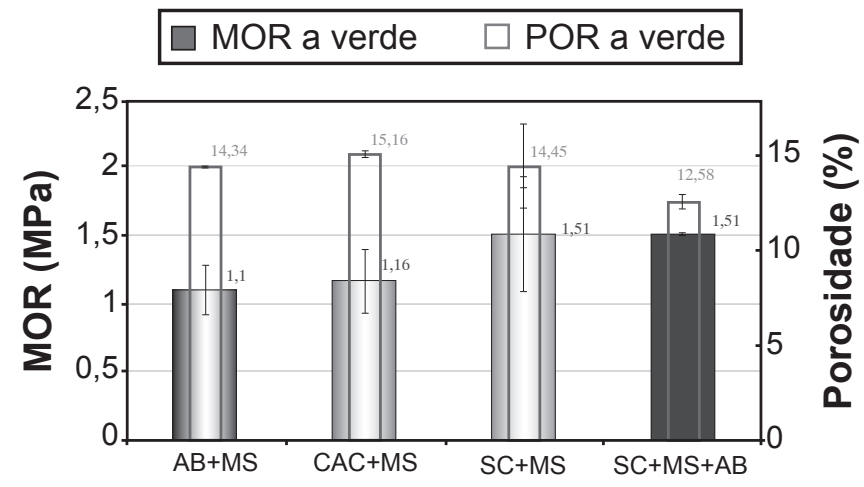

Figura 1: Resistência mecânica (MOR) e porosidade (POR) a verde.

[Figure 1: Mechanical resistance (MOR) and porosity (POR) of green samples.]

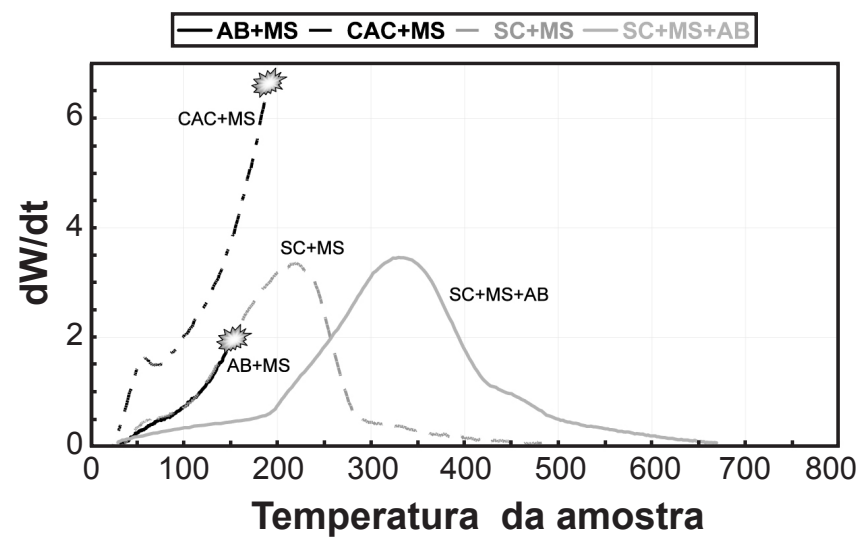

Figura 2: Ensaio de explosão a uma taxa de aquecimento de $20^{\circ} \mathrm{C} /$ $\min$.

[Figure 2: Explosion test under a heating rate of $\left.20{ }^{\circ} \mathrm{C} / \mathrm{min}.\right]$

rapidamente, enquanto os ligados por sílica sol suportaram a solicitação, uma vez que este ligante não é hidráulico e possui nano poros que facilitam a retirada da água. Sendo assim, o risco de explosão neste sistema é baixo e o tempo de secagem inferior.

Importante notar que o sistema $\mathrm{AB}+\mathrm{MS}$ não suporta a solicitação e explodiu a aproximadamente $150{ }^{\circ} \mathrm{C}$, enquanto que o sistema $\mathrm{SC}+\mathrm{MS}+\mathrm{AB}$ resistiu ao teste. Ambos os sistemas são constituídos da mesma formulação, sendo o segundo acrescido de 5\% de sílica coloidal, o que comprova a eficácia do ligante coloidal na redução do risco de explosão.

\section{Resultados após queima}

Tanto a porosidade quanto a resistência mecânica após queima apresentaram valores distintos para os sistemas analisados. As formulações contendo Alfabond obtiveram resistência mecânica inferior aos demais, pois durante a cura, este ligante forma um gel [4] que diminui a permeabilidade e dificulta a saída da água da estrutura, gerando fortes tensões internas que causam trincas e defeitos durante a secagem.

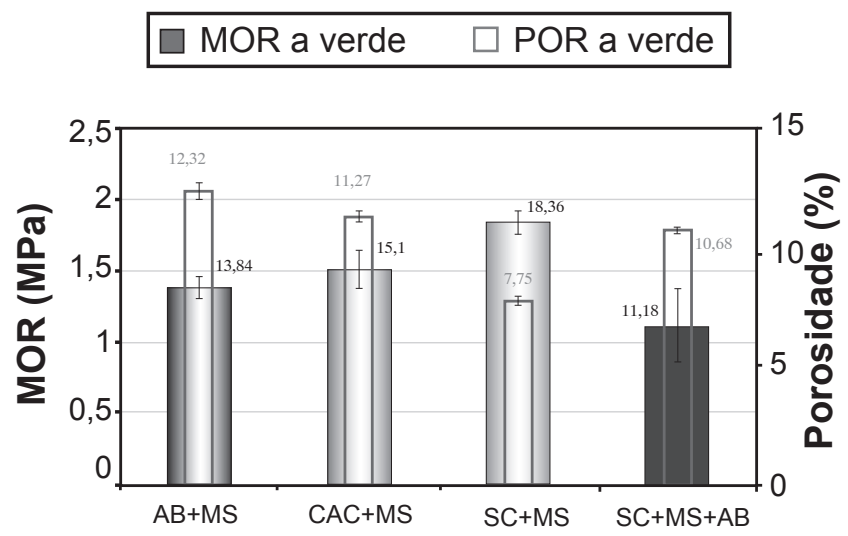

Figura 3: Resistência mecânica (MOR) e porosidade (POR) após queima a $1500{ }^{\circ} \mathrm{C}$ por $10 \mathrm{~h}$.

[Figure 3: Mechanical strength (MOR) and porosity (POR) for samples sintered at $1500{ }^{\circ} \mathrm{C}$ for $10 \mathrm{~h}$.]

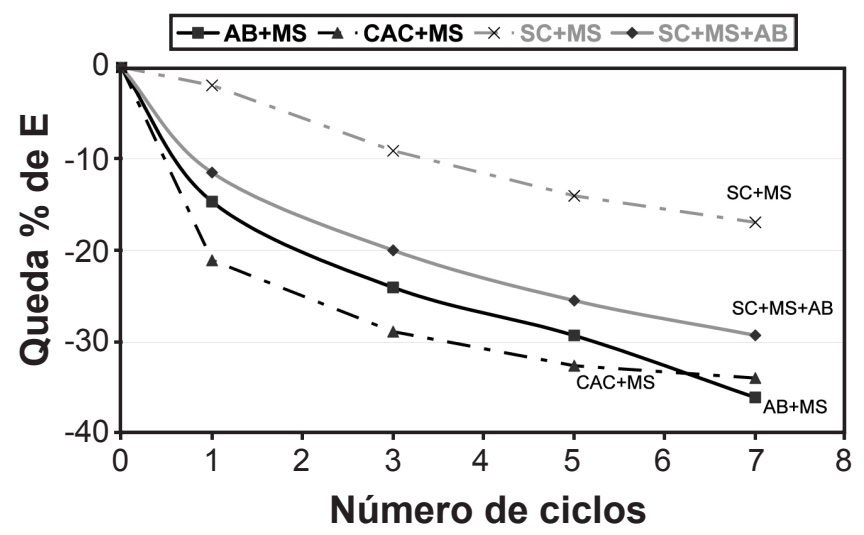

Figura 4: Queda percentual do módulo elástico em função dos ciclos térmicos $\left(\Delta \mathrm{T}=975^{\circ} \mathrm{C}\right)$.

[Figure 4: Elastic Modulus percentage decrease as a function of thermal cycles $\left(\Delta T=975^{\circ} \mathrm{C}\right)$.]

Como consequiência, o módulo de ruptura é reduzido e a porosidade aumentada.

A formulação SC+MS apresentou resistência mecânica após queima superior às demais composições, pois a facilidade de secagem deste ligante gera menor quantidade de defeitos estruturais. Como conseqüência sua porosidade apresentou-se inferior aos outros sistemas (Fig. 3), devido ao ligante coloidal não conter água estrutural e possuir alta reatividade [9], o que auxilia a sinterização das amostras. Todos os sistemas foram projetados visando obter porosidade a verde semelhante (curva de empacotamento de Andreasen com $\mathrm{q}=0,21)$, portanto, as diferenças nos valores de porosidade após a queima se deram principalmente devido a sinterabilidades distintas. Na Fig. 4, que mostra a queda do módulo elástico em função dos ciclos de choque térmico, a formulação SC+MS obteve desempenho significativamente superior às demais. Uma vez que as formulações estudadas visam à obtenção de mulita na estrutura, e que esta fase apresenta boa resistência ao choque térmico, este resultado foi atribuído a elevada reatividade das nano partículas de $\mathrm{SiO}_{2}$, resultando em maior mulitização no sistema. 


\section{Resultados a quente}

Os resultados das Figs. 5 e 6 simulam o desempenho dos concretos durante o uso. Na Fig. 5 é importante ressaltar que em todas as temperaturas ensaiadas, o sistema SC+MS obteve resultado superior, principalmente a $1450{ }^{\circ} \mathrm{C}$. Esse resultado, a principio, pode ser um indicativo do maior teor de mulita formada, menor quantidade de fase líquida residual, e menor trincamento da estrutura devido ao ligante coloidal não possuir água de hidratação.

A reação de mulitização inicia-se com a interdifusão de íons alumínio e silício nas interfaces de partículas de $\mathrm{Al}_{2} \mathrm{O}_{3}$ e $\mathrm{SiO}_{2}$ [10]. Preferencialmente, os íons provenientes da alumina se difundem para o interior da sílica [11-13], destruindo sua estrutura e amorfizando a região. Dessa forma, um líquido meta-estável de alta viscosidade é gerado, que acelera a difusão destes óxidos. Conforme a temperatura é aumentada, mais íons alumínio são dissolvidos no líquido e o mesmo se enriquece em alumina, formando a ligação Si-O-Al. A nucleação de mulita se estabelece quando as quantidades de sílica e alumina alcançam a proporção

$\square 815^{\circ} \mathrm{C} \square 1200^{\circ} \mathrm{C} \square 1300^{\circ} \mathrm{C} \square 1400^{\circ} \mathrm{C} \quad \square 1450^{\circ} \mathrm{C}$

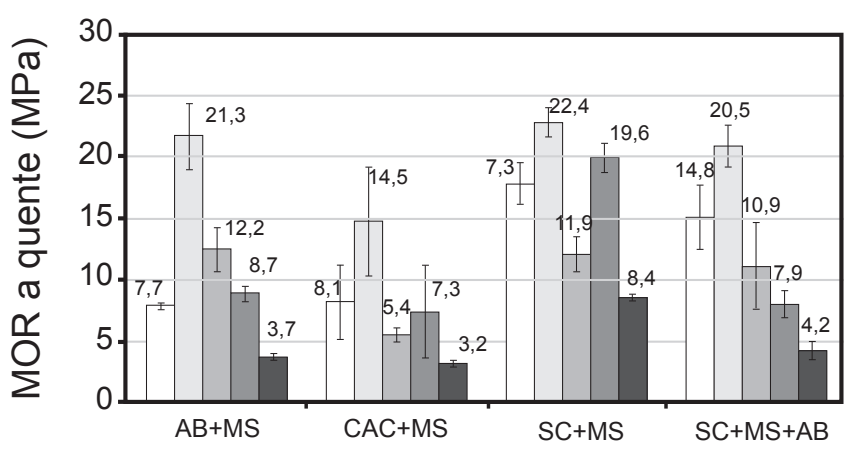

Figura 5: Resistência mecânica a quente (MRQ) em corpos préqueimados por $10 \mathrm{~h}$ a $815,1200,1300,1400,1450{ }^{\circ} \mathrm{C}$.

[Figure 5: Hot mechanical strength (MRQ) for the samples sintered for $10 \mathrm{~h}$ at the following temperatures: 815, 1200, 1300, 1400, $\left.1450^{\circ} \mathrm{C}.\right]$

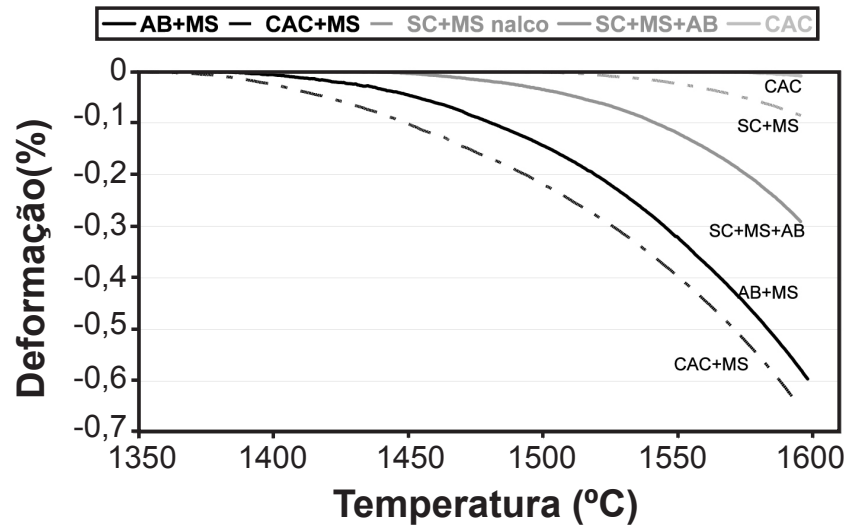

Figura 6: Refratariedade sobre carga $(0,2 \mathrm{MPa})$ para as composições.

[Figure 6: Refractoriness under load (0.2 MPa) for the compositions.] estequiométrica da fase. Conforme a temperatura é elevada, mais íons alumínio são dissolvidos no líquido silicoso e consequentemente mais mulita é precipitada na estrutura. Uma vez atingido o patamar de temperatura, a dissolução da $\mathrm{Al}_{2} \mathrm{O}_{3}$ cessa, e o líquido restante que não precipitou em mulita se mantém na estrutura como fase vítrea residual. Portanto, a utilização de fontes de $\mathrm{SiO}_{2}$ e $\mathrm{Al}_{2} \mathrm{O}_{3}$, ambas reativas, onde a interdifusão dos íons se inicie em baixas temperaturas, antecipa o aparecimento da mulita e resulta em maior teor da mesma e, consequentemente, em menor teor de líquido residual para a mesma temperatura de queima. Desta maneira, é possível afirmar que quanto maior a quantidade de mulita na estrutura de sistemas sílico-aluminosos, menor o teor de fase vítrea residual, pois boa parte da sílica que não mulitiza durante a queima permanece na estrutura como um líquido silico aluminoso. Esse líquido metaestável é o principal responsável pela redução do módulo de ruptura a quente nos concretos ensaiados [14]. Uma análise mais detalhada da Fig. 5, para os sistemas CAC+MS e SC+MS, revela um perfil típico da reação via fase líquida acima descrita [14]. A $815{ }^{\circ} \mathrm{C}$, o valor de resistência é baixo devido a pouca sinterização do sistema; a $1200{ }^{\circ} \mathrm{C}$ esse valor aumenta devido a formação de ligação cerâmica entre as partículas (sinterização); em torno de $1250{ }^{\circ} \mathrm{C}$ inicia-se a formação de fase líquida meta-estável, intrínseca da reação de mulitização. Tal efeito pode ser observado pelo ensaio a $1300{ }^{\circ} \mathrm{C}$ que resulta em uma grande redução do MRQ devido a quantidade de fase líquida no sistema; a $1350{ }^{\circ} \mathrm{C}$, a precipitação do líquido em cristais de mulita ganha grandes proporções, levando ao aumento do módulo de ruptura a quente a $1400{ }^{\circ} \mathrm{C}$. A $1450{ }^{\circ} \mathrm{C}$ o valor volta a cair novamente devido a elevada severidade do ensaio nessa temperatura. As formulações contendo Alfabond não apresentaram esse perfil, pois a alta área superficial apresentada pela @-alumina é principalmente devido aos micro canais nas partículas e não a um tamanho de partícula reduzido. Desta forma, a alumina hidratável sofre uma auto-sinterização, gerando grãos grandes e estáveis, causando o efeito contrário ao esperado para se obter alta mulitização. Como resultado, os sistemas contendo esse ligante provavelmente mulitizaram em menor grau e consequentemente resultaram em uma quantidade grande de fase vítrea residual em sua estrutura. O sistema SC+MS apresentou o maior valor de MRQ na temperatura de $815{ }^{\circ} \mathrm{C}$ devido a maior sinterabilidade, seguido do sistema $\mathrm{SC}+\mathrm{MS}+\mathrm{AB}$. Estes resultados comprovam a alta sinterabilidade do ligante nanométrico. Os baixos valores de MRQ para o sistema CAC+MS se devem principalmente a presença de $\mathrm{CaO}$, que reduz significativamente a viscosidade do líquido metaestável e aumenta a quantidade do mesmo [13]. No ensaio de refratariedade sob carga (Fig. 6), um sistema de alta alumina ligado por cimento e sem a adição de sílica foi utilizado como referência, uma vez que o mesmo possui alta refratariedade. As deformações apresentadas na Fig. 6, são principalmente devido a fase líquida na estrutura. O sistema referência de alta alumina praticamente não se deforma devido a sua alta refratariedade. O sistema SC+MS deforma muito pouco, apresentando uma temperatura de 
trabalho superior a $1600{ }^{\circ} \mathrm{C}$, o que comprova o pequeno teor de líquido residual presente. Sendo assim, em ordem crescente de deformação, têm-se os sistemas $\mathrm{SC}+\mathrm{MS}+\mathrm{AB}$, $\mathrm{AB}+\mathrm{MS}$ e $\mathrm{CAC}+\mathrm{MS}$, sendo este último o que apresenta maior deformação devido a combinação de $\mathrm{Al}_{2} \mathrm{O}_{3}, \mathrm{SiO}_{2} \mathrm{e}$ $\mathrm{CaO}$, que pode levar a formação de guelenita e anortita.

\section{CONCLUSÕES}

A sílica coloidal possui poder de ligação a verde equivalente aos ligantes hidráulicos comumente usados, e que se destaca devido a três fatores: nanoporosidade do gel formado, ausência de água estrutural (ligante não hidráulico) e alta reatividade das nano partículas de sílica. As duas primeiras características implicam em maior facilidade de secagem e grande redução do risco de explosão no sistema. A segunda, em maior sinterização e mulitização na matriz. Estes resultados, se correlacionados com a teoria, onde o maior teor de mulita implica em menor quantidade de fase líquida residual, reafirmam a superioridade da sílica coloidal na mulitização, comprovam o efeito deletério do CAC em concretos contendo $\mathrm{SiO}_{2}$ e ainda indicam que a alumina hidratável apesar da alta reatividade não é um bom agente mulitizador, pois dificulta a reação da alumina com a sílica.

A alta reatividade das nanopartículas repercute de maneira positiva nas propriedades a quente, no grau de mulitização e na quantidade de fase líquida residual dos concretos.

\section{AGRADECIMENTOS}

Os autores agradecem a CNPq pela ajuda financeira, a empresa Forza do Brasil pelo suporte técnico e aos pesquisadores Fernando Valenzuela e Matheus Piva pela colaboração.

\section{REFERÊNCIAS}

[1] N. Zhou, S. Hu, S. Zhang, Advances in modern refractory castable, China`s Refractories 13, 2 (2004) 3-12.
[2] C. M. Peret, J. A. Gregolin, L. I. L. Faria, V. C. Pandolfelli, Patent generation and the technological development of refractories and steelmaking, Refract. Appl. News 12, 1 (2007)10-14.

[3] C. Parr, C. Wohrmeyer, The advantages of calcium aluminate cement as a castable bonding system, Lafarge Aluminates Paris, França.

[4] F. A. Cardoso, M. D. M. Innocentini, M. F. S. Miranda, F. A. O. Valenzuela, V. C. Pandolfelli, Drying behavior of hydratable alumina - Bonded refractory castable, J. Eur. Ceram. Soc. 24, 5 (2004) 797-802.

[5] Y. Hongo, @-Alumina bonded castable refractories, Taikabutsu Overseas 9, 1 (1989) 35-38.

[6] M. R. Ismael, Sílica coloidal como agente ligante para concretos refratários, Diss. Mestrado, EdUFSCar, S. Carlos, SP (2006).

[7] K. R. Iler, The chemistry of silica, John Wiley and Sons, Nova York, EUA (1979) 312-439.

[8] R. G. Pileggi, V. C. Pandolfelli, Reologia e distribuição granulométrica de concretos refratários bombeáveis, Cerâmica 48, 305 (2002) 11-16.

[9] Sílica Sols from Bayer - Catalogo Técnico Levasil.

[10] M. Schneider, K. Okada, J. A. Pask, Mullite and mullite ceramics, John Wiley \& Sons, Nova York, EUA (1994) 83145.

[11] I. A. Aksay, J. A. Pask, Stable and metastable equilibria in the system $\mathrm{SiO}_{2}-\mathrm{Al}_{2} \mathrm{O}_{3}$, J. Am. Ceram. Soc. 58, 11-12 (1975) 507-512.

[12] S. H. Risbud, J. Pask, $\mathrm{SiO}_{2}-\mathrm{Al}_{2} \mathrm{O}_{3}$ metastable phase equilibrium diagram without mullite, J. Mater. Sci. 13 (19978) 2449-2454.

[13] S. M. Johnson, J.A.Pask, Role of impurities on formation of mullite from kaolinite and $\mathrm{Al}_{2} \mathrm{O}_{3}-\mathrm{SiO}_{2}$ mixtures, $\mathrm{Am}$. Ceram. Soc. Bull. 61, 8 (1982) 838-842.

[14] M. V. Gerotto, Concretos refratários aluminosos com matrizes mulíticas pela adição de microssílica caulim ou metacaulim, Diss. Mestrado, EdUFSCar, S. Carlos, SP (2000).

(Rec. 29/03/2008, Ac. 01/08/2008) 